\title{
Electrochemical study on Surface Oxidation of Natural Pyrite in Ferric Sulfate Solution
}

\author{
Guobao Chen, Hongying Yang
}

School of Metallurgy, Northeastern University, Shenyang 110819, Liaoning, China E-mail: chengb@smm.neu.edu.cn

doi: $10.20964 / 2019.08 .90$

Received: 10 March 2019 / Accepted: 10 May 2019 / Published: 30 June 2019

\begin{abstract}
Surface oxidation of natural massive pyrite in $0.5 \mathrm{M}$ sulfuric acid solutions with different ferric concentrations was investigated. The electrode of natural pyrite was made and its behavior was measured using cyclic voltammetry (CV), linear sweep voltammetry (LSV) and rotating disk electrode (RDE). According to the test results, the open circuit potential (OCP) of pyrite grew steadily when the ferric concentration increased. Furthermore, the rate of pyrite oxidation was strengthened with the addition of ferric ions. However, it is difficult to distinguish the chemical or electrochemical oxidation on pyrite and their interaction process. Here, the electron transferred numbers (ETNs) of oxidation processes on pyrite were calculated. And it is found the ETN could be a useful tool to compare rapidly the oxidation reactivity for different conditions. The overall surface oxidation process on pyrite occurred in the potential range of $-0.450 \mathrm{~V}$ to $0.050 \mathrm{~V}$ vs. $\mathrm{AgCl} / \mathrm{Ag}$. The average ETN for pyrite oxidation was around 2 in sulfuric acid. The increasing of ferric ion was found to affect ETN markedly while the polarization current was raised, which indicate that the pyrite electrochemical oxidation was inhibited by adding ferric ions, and the dissolution was the main result of chemical oxidation. Moreover, the studies of the surface oxidation on pyrite with adding silver ion and that on chalcopyrite were also conducted to confirm the new founds. Silver ion is inferred to be difficult to form silver atoms and influence the oxygen electrochemical oxidation less.
\end{abstract}

Keywords: Surface oxidation; Pyrite; Rotating disc electrode; Electron transferred numbers; Ferric ion

\section{$\underline{\text { FULL TEXT }}$}

(C) 2019 The Authors. Published by ESG (www.electrochemsci.org). This article is an open access article distributed under the terms and conditions of the Creative Commons Attribution license (http://creativecommons.org/licenses/by/4.0/). 